\title{
Environment-Sensitive Behaviour of Welds: Challenges in Microstructural Characterisation
}

\author{
M. G. Burke, S. Schilling and A. Welbourne \\ School of Materials, University of Manchester, Manchester, UK
}

In power generation systems, welds merit significant consideration and concern, particularly in terms of environment-sensitive behaviour. Failure phenomena such as environmentally-assisted cracking (EAC), stress corrosion cracking (SCC) and corrosion fatigue $(\mathrm{CF})$ in primary water systems can occur, depending on the material, its prior processing, and subsequent thermal history. For welds, the heataffected zone (HAZ) can represent a special region of interest/concern due to the microstructural changes that can occur during welding, as well as residual stress considerations. To assess the susceptibility of the weld HAZ to EAC and SCC, surrogate material is frequently employed. In evaluating the HAZ, hardness measurements are generally performed, and it is recognised that the hardness of the HAZ tends to be notably greater than the surround base metal. Thus, tests to simulate the weld HAZ have involved cold-rolling the alloy of interest to obtain the increase hardness. This study involves the characterisation of an Alloy 690 Control Rod Drive Mechanism casing that contained two Alloy 52 welds. Alloy 690 is a Ni-base alloy that contains approximately $30 \mathrm{wt} . \% \mathrm{Cr}-9 \mathrm{wt} \% \mathrm{Fe}-$ 0.2 wt. $\% \mathrm{Mn}-0.3$ wt. $\% \mathrm{Ti}-0.03$ wt. $\% \mathrm{C}$ - bal Ni. Alloy 52 (or Filler Metal 52) is the related weld filler metal alloy ( 30\% wt.\% Cr - 9 wt. $\% \mathrm{Fe}-0.6$ wt.\% $\mathrm{Mn}-0.5$ wt. $\% \mathrm{Ti}-0.2$ wt. $\% \mathrm{C}-$ bal Ni).

Samples for subsequent microstructural analysis were taken along the weld fusion line so that they contained the HAZ. TEM characterisation of electron-transparent thin-foil specimens was performed using an FEI $300 \mathrm{kV}$ Tecnai T30 equipped with an Oxford Instruments Xmax80 silicon drift detector, and a Philips CM20 transmission electron microscope.

Figure 1a shows the light optical micrograph of the Alloy 52 weld with the adjacent Alloy 690 HAZ. TEM analysis of HAZ specimens revealed that the increased hardness of this zone was associated with a dislocated microstructure, as expected. However, unlike the deformation structures associated with room temperature deformation of this face-centered cubic alloy, the HAZ revealed very little evidence of planar slip. In contrast to the presence of numerous slip bands, the deformation structures in the HAZ consisted of numerous dislocations with evidence of cross-slip and climb, as well as dislocation loops. The TEM images of Figure $1 \mathrm{~b}$ and 1c provide representative examples of the HAZ deformation structures. These structures were inconsistent with low temperature deformation, but indicated that the strain experienced in the HAZ occurred at elevated temperatures. In addition to the deformation structures, particular attention was given to the assessment of intergranular carbide precipitation in the HAZ. However, very little additional intergranular precipitation was observed in the region. This research is continuing, but it demonstrates the importance of detailed characterisation to ensure that the surrogate materials used for the evaluation of the SCC, EAC and CF reflect the relevant microstructures (particularly deformation structures) for a true assessment of the environment-sensitive behavior of the HAZ.

Acknowledgement: The welds were kindly provided by Drs. E. Willis and S. McCracken of the Electric Power Research Institute. 


\section{Fusion}

1a )

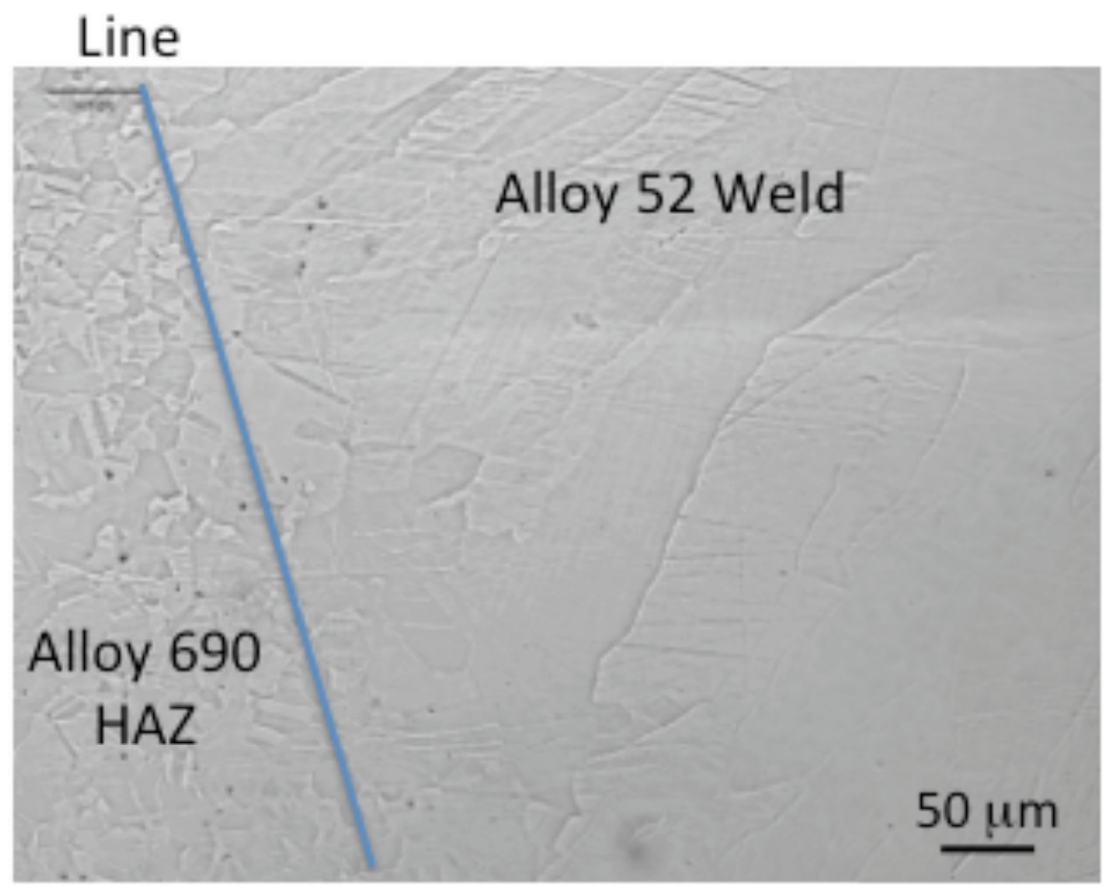

LOM- OPS final polish
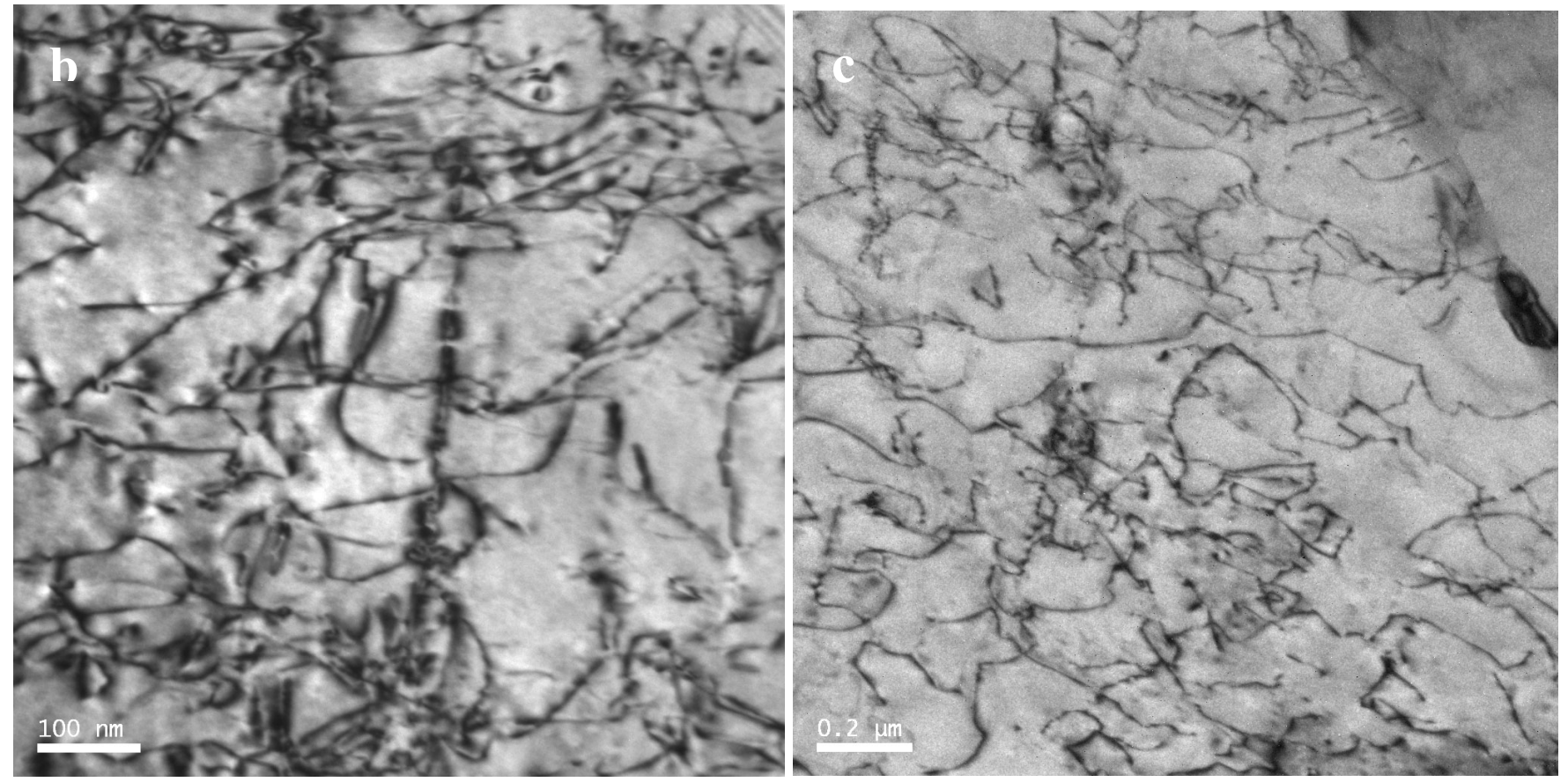

Figure 1. (a) Light optical micrograph of an Alloy 690/Alloy 52 weld; (b) and (c) Bright-field TEM images of the deformation structures in the HAZ. Note that the dislocation structures suggest deformation occurred at elevated temperatures. 